\title{
Exhaled carbon monoxide: a non-invasive biomarker of short-term exposure to outdoor air pollution
}

Herve Lawin ${ }^{1,2^{*}}$, Lucie Ayi Fanou ${ }^{3}$, Vikkey Hinson ${ }^{1}$, Jacqueline Wanjiku4, N. Kingsley Ukwaja ${ }^{5}$, Stephen B Gordon ${ }^{6}$, Benjamin Fayomi', John R Balmes ${ }^{7}$, Parfait Houngbegnon², Euripide Avokpaho ${ }^{1}$ and Ambaliou Sanni ${ }^{3}$

\begin{abstract}
Background: In urban settings of Africa with rapidly increasing population, traffic-related air pollution is a major contributor to outdoor air pollution (OAP). Although OAP has been identified as a leading cause of global morbidity and mortality, there is however, lack of a simple biomarker to assess levels of exposure to OAP in resource-poor settings. This study evaluated the role of exhaled carbon monoxide (exhCO) as a potential biomarker of exposure to ambient carbon monoxide (ambCO) from OAP.
\end{abstract}

Methods: This was a descriptive study conducted among male commercial motorcycle riders in Cotonou the economic capital of Benin. The participants' AmbCO was measured using a portable carbon monoxide (CO) data logger for $8 \mathrm{~h}$ during the period of their shift. ExhCO was measured just before and immediately after their shift (8-h) Participants were asked not to cook or to smoke during the day of the measurements. Linear regression analysis was used to assess the association between ambCO and exhCO for the last 2, 4 and $6 \mathrm{~h}$ of their shift.

Results: Of 170 participants who completed the study, their mean \pm SD age was $42.2 \pm 8.4$ years, and their mean \pm SD daily income was $7.3 \pm 2.7 \$$. Also, $95 \%$ of the participants' used solid fuels for cooking and only $2 \%$ had ever smoked. Average exhCO increased by $5.1 \mathrm{ppm}$ at the end of the shift ( $p=0.004)$. Post-shift exhCO was significantly associated to ambCO, this association was strongest for the last $2 \mathrm{~h}$ of OAP exposure before exhCO measurement ( $\beta=0.34, p<0.001$ ).

Conclusion: ExhCO level was associated with recent exposure to ambCO from OAP with measurable increase after $8 \mathrm{~h}$ of exposure. These findings suggest that ExhCO may be a potential biomarker of short-term exposure to OAP.

Keywords: Carbon monoxide, Air pollution, Biomarker

\section{Background}

Outdoor air pollution (OAP) especially from vehicular traffic is of growing importance since it occurs largely in urban areas expected to constitute $66 \%$ of the world population by 2050 [1]. According to the United Nations [1], much of the expected urban growth will take place in low and middle-income countries (LMICs),

\footnotetext{
* Correspondence: hervelawin@yahoo.fr

'Unit of Teaching and Research in Occupational and Environmental Health, Department of Public Health, Faculty of Health Sciences, University of Abomey-Calavi, Cotonou, Benin

${ }^{2}$ Institut Regional de Santé Publique, University of Abomey Calavi, Cotonou, Benin

Full list of author information is available at the end of the article
}

particularly Africa. The 68th United Nations World Health Assembly called for action to reduce the burden of OAP in LMICs [2]. Taking action to reduce exposure to OAP warrants the assessment of the exposure level through personal and environmental monitoring.

Several epidemiologic studies have found that ambient air pollution (from generators, vehicular emissions, agriculture and open burning, and household air pollution) is associated with risk of developing a broad range of diseases [3-5]. Ambient air pollution, for example particulate matter [6], is classified by the International Agency for Research on Cancer (IARC) as a group 1 carcinogen to humans lungs [7]. Sulphur dioxide (SO2), 
Nitrous oxide (NOX), carbon monoxide (CO) and low molecular weight particulate matter (e.g. $\mathrm{PM}_{2.5}$ ) from traffic-related air pollution (TRAP) are likely important contributors to OAP and have been extensively measured. Several potential biomarkers of OAP have been studied e.g., fraction of exhaled nitric oxide (FeNO), spirometry parameters, constituent cytokines, exhaled breath condensate, and induced sputum [8]; however, these measurements need technical expertise and may be expensive to carry out. In addition, they cannot be performed routinely in developing countries where the burden of OAP may be substantial and the majority of exposed urban citizens live.

Exhaled carbon monoxide (exhCO) has been used routinely and successfully for monitoring in the context of tobacco smoking cessation $[9,10]$. Hence, it is conceivable that it could be used as an index of exposure to other air pollution sources other than tobacco smoking such as ambient air pollution which contains $\mathrm{CO}$. $\mathrm{CO}$ rapidly combines with hemoglobin to form carboxyhemoglobin when inhaled; and its concentration in ambient air and duration of exposure are the most important determinants of carboxyhemoglobin saturation $[11,12]$. The half-life of inhaled $\mathrm{CO}$ varies from 2 to $6 \mathrm{~h}$ depending on physiologic factors such as respiratory rate, making it a potential marker of recent exposure $[13,14]$. Few studies have evaluated the correlation between exhCO with exposures from $\mathrm{CO}$ in solid fuels used in the households $[15,16]$, but none examined its relationships with OAP exposures. This study aimed to assess changes in exhCO over a shift of $8 \mathrm{~h}$ and its relationship with $\mathrm{CO}$ exposures following a short-term exposure to OAP in exposed males in Cotonou. Cotonou is the economical capital of Benin and has a quite elevated level of pollutants $[17,18]$. We hypothesized that exhaled $\mathrm{CO}$ will increase over the shift and the post-shift exhaled $\mathrm{CO}$ will be associated with the mean value of $\mathrm{CO}$ measurement in ambient air of the last 2, 4 and $6 \mathrm{~h}$ of exposure.

\section{Methods}

\section{Study design and population}

This cross-sectional study included 170 male commercial motorcycle riders exposed to $\mathrm{CO}$ from OAP in Cotonou, the economical capital of Benin, an urban area with a lot of traffic, and hence high OAP.

The recruitment plan has been described extensively elsewhere [3]. Briefly we recruited 85 commercial motorcycle riders working in Cotonou and individually matched controls. The controls included civil servants and craftsmen mainly also working in Cotonou. All participants were asked not to smoke or be involved in cooking activities during the day of the measurement.

\section{Data collection and measurement}

\section{Questionnaire (see Additional file 1)}

We recorded socio-demographic data including age, marital status, educational level and daily income. In addition, we collected data on any physician-diagnosed medical condition such as; lung cancer, heart disease, tuberculosis, stroke, high blood pressure, diabetes, emphysema, asthma, chronic bronchitis or chronic obstructive pulmonary disease. Each co-morbidity was assessed individually but for this analysis, results were pooled and only the variable "any co-morbidity" was considered. Similarly we defined "any tobacco exposure" as ever smoking or exposure to environmental tobacco smoke. This has been pooled this way in order to put together all the source of $\mathrm{CO}$ from tobacco exposure other than ambient air pollution. We also collected data on their exposure to biomass (wood, coal, kerosene, crop residues) from cooking in their household.

\section{Outdoor air pollution exposure}

Carbon monoxide in ambient air (ambCO) was measured with a pre-calibrated portable $\mathrm{CO}$ data logger with a USB interface El-USB-CO ${ }^{\circ}$ (Lascar Electronics, Whiteparish Salisbury, UK). All the participants carried the device for $8 \mathrm{~h}$ per day during working hours with a logging rate of $5 \mathrm{~min}$. The device was hung around their neck before starting their working day and was removed $8 \mathrm{~h}$ later at the end of their shift.

\section{Exhaled CO}

exhCO was measured before and at the end of the shift using a CO Check $+{ }^{\bullet}$ (MD Diagnostics Ltd., Maidstone, Kent, UK). The CO Check $+{ }^{\circ}$ is a portable device in which participants were asked to blow through a disposable mouthpiece for about 10 to $15 \mathrm{~s}$. Two measurements were done, and if not identical a third one was repeated. The average of the three measurements was then reported. The device was calibrated using a $20 \mathrm{ppm}$ $\mathrm{CO}$ in air calibration gas prior to all the measurements. The measurements were done in our local laboratory where the environmental $\mathrm{CO}$ was close to zero.

\section{Spirometry}

Spirometry was performed at the beginning of the study by each participant in the morning hours. The study participants completed spirometry according to the American Thoracic Society and European Respiratory Society guidelines [19] with an EasyOne ${ }^{\circ}$ Spirometer (ndd, Switzerland) calibrated daily with a 3-L syringe. The spirometric procedure included at least 3 acceptable and repeatable forced vital capacity maneuvers. All the tests were reviewed by an external investigator and the best value was selected for analysis. We reported the abnormal lung function including obstructive and restrictive patterns. 


\section{Data analysis}

Individuals with incomplete records (technical problems from the devices handling, $n=17$ ) were excluded from the analysis. Mean values of the initial and the end of the shift exhCO were compared using $t$ - test. Mean values of ambCO for the last 2, 4 and $6 \mathrm{~h}$ before the measurement of the exhCO at the end of the working day were also compared using t-test. This range of time was used relative to the half life of $\mathrm{CO}$ which is 2 to $6 \mathrm{~h}$ depending on physiologic factors such as respiratory rate, making it a potential marker of recent exposure $[13,14]$. A linear regression analysis was developed to assess the association between exhCO at the end of the shift and the ambCO for the last 2, 4 and $6 \mathrm{~h}$ of exposure. We adjusted for exposure to tobacco smoke, exposure to biomass, any co-morbidity, abnormal lung function and marital status. Regression coefficient was calculated. The statistical significance was set to 0.05. Analysis was done using Stata 12.

\section{Results}

\section{Characteristics of the study participants}

The mean \pm SD age of our study population was $42.2 \pm 8.4$ years and they had a low income (Table 1). More than $90 \%$ were exposed to biomass smoke, and $32.5 \%$ reported exposure to tobacco smoke including 3 current smokers and 1 ex smoker.

\section{Exposures measurement}

Mean \pm SD exhCO increased from $13.4 \pm 7.6 \mathrm{ppm}$ (pre shift) to $18.5 \pm 9.5 \mathrm{ppm}$ (post shift) $(p=0.004)$ as shown in Table 2.

Table 1 Characteristics of study participants

\begin{tabular}{ll}
\hline Characteristic & Summary \\
\hline Age (years) - mean (SD) & $42.2(8.4)$ \\
Income per day $(\$)^{\mathrm{a}}-$ mean (SD) & $7.3(2.7)$ \\
Marital status n (\%) & \\
Married & $150(98)$ \\
Unmarried (single or widow) & $3(2)$ \\
Education level n (\%) & \\
None & $22(14.4)$ \\
Primary school & $75(49.1)$ \\
College & $21(13.7)$ \\
High school & $32(20.9)$ \\
University & $3(1.9)$ \\
Biomass exposure $\mathrm{n}(\%)$ & $144(94.7)$ \\
Exposure to tobacco smoke n (\%) & $51(33.3)$ \\
Any co-morbidity $\mathrm{n}(\%)$ & $29(19)$ \\
Abnormal Lung function $\mathrm{n}(\%)$ & $23(15)$ \\
\hline
\end{tabular}

${ }^{\mathrm{a}} 1 \$=500 X O F$ (Local currency in Benin)
Table 2 Level of exhaled carbon monoxide and carbon monoxide in ambient air level

\begin{tabular}{llll}
\hline Variables & Mean & Standard deviation & $\mathrm{p}$ \\
\hline Baseline exhCO (ppm) & 13.4 & 7.6 & \\
$\begin{array}{l}\text { exhCO at the end of the working } \\
\text { day (ppm) }\end{array}$ & 18.5 & 9.5 & 0.004 \\
2 last hours ambCO ${ }^{\mathrm{a}}$ & 5.6 & 4.4 & \\
4 last hours ambCO & & & \\
6 last hours ambCO & & & \\
ambCO & 5.7 & 4.5 & \\
& 6.3 & 4.7 &
\end{tabular}

ambCO ambient carbon monoxide, exhCO exhaled carbon monoxide ${ }^{a}$ Mean values of ambCO before the measurement of exhCO at the end of the working day (in ppm)

\section{Association between exhaled $\mathrm{CO}$ at the end of the working day and $\mathrm{CO}$ in ambient air}

Exhaled $\mathrm{CO}$ at the end of the shift was significantly associated to exposure to ambCO during the last 2, 4 and $6 \mathrm{~h}$, even after adjusting for potential confounders. This association was stronger for ambCO measured over the most recent $2 \mathrm{~h}$ (regression coefficient $\beta=0.34$ ) than for 4 and $6 \mathrm{~h}$ (regression coefficients of 0.22 and 0.14 , respectively) (see Table 3 ).

The difference between exhCO in the morning and the end of the working day $(\triangle \mathrm{exhCO})$ was significantly associated to the mean of the 2 last hours ambCO (regression coefficient $\beta=0.41, p=0.008$ ) and 4 last hours ambCO (regression coefficient $\beta=0.21, p=0.01$ ) after adjustment on the same potential confounders as in Table 3 .

\section{Discussion}

We are not aware of other studies that have assessed the relationship between exhaled $\mathrm{CO}$ and short-term exposure to $\mathrm{CO}$ in ambient air from outdoor air pollution, especially traffic emissions. We have demonstrated that exhaled $\mathrm{CO}$ had a stronger association to 2-h ambient CO exposure $(\beta=0.34, p<0.001)$ compared with the last 4 and $6 \mathrm{~h}$ of exposure. The weaker association of the exhaled $\mathrm{CO}$ to the average values of the last 4 and $6 \mathrm{~h}$ $\mathrm{CO}$ exposure may be due to the half-life of the inhaled $\mathrm{CO}$. The half-life of $\mathrm{CO}$ is $2-6 \mathrm{~h}$ and it is thus understandable that exhCO might better reflect the most recent 2-h exposure. Moreover, we found a significant difference between the measurements of baseline exhCO and exhCO at the end of the 8-h shift. This difference was strongly associated with the average values of the 2 last hours of exposure to $\mathrm{CO}$ from outdoor air pollution. The baseline exhaled $\mathrm{CO}$ was $13.4 \pm 7.6 \mathrm{ppm}$ and this is higher than the cut-off value of 6 to 9 ppm commonly used to distinguish smokers from non-smokers [14, 20]. Although the baseline elevation in exhaled $\mathrm{CO}$ could be related to other causes, it is most likely related to the ambient exposure the study participants were exposed to before they arrived at our local laboratory in the 
Table 3 Exposure-response between exhaled $\mathrm{CO}$ at the end of the working day and $\mathrm{CO}$ in ambient air

\begin{tabular}{|c|c|c|c|c|c|c|c|c|c|}
\hline & \multicolumn{3}{|c|}{2 last hours $\mathrm{AmbCO}$} & \multicolumn{3}{|c|}{4 last hours $\mathrm{AmbCO}$} & \multicolumn{3}{|c|}{6 last hours $\mathrm{AmbCO}$} \\
\hline & $\overline{\beta^{a}}$ & $\beta^{\mathrm{b}}$ & $p$ & $\overline{\beta^{a}}$ & $\beta^{b}$ & $p$ & $\overline{\beta^{a}}$ & $\beta^{b}$ & $p$ \\
\hline exhCO at the end of the shift & 0.31 & 0.34 & $<0.001$ & 0.20 & 0.22 & $<0.001$ & 0.13 & 0.14 & 0.01 \\
\hline Exposure to tobacco smoke & & 0.12 & 0.17 & & 0.17 & 0.27 & & 0.11 & 0.54 \\
\hline Exposure to biomass & & 0.07 & 0.08 & & 0.09 & 0.13 & & 0.19 & 0.10 \\
\hline Any comorbidities & & 0.11 & 0.14 & & 0.12 & 0.14 & & 0.09 & 0.14 \\
\hline Abnormal lung function & & 0.01 & 0.25 & & 0.03 & 0.20 & & 0.05 & 0.18 \\
\hline Marital status & & 0.02 & 0.28 & & 0.01 & 0.21 & & 0.04 & 0.16 \\
\hline
\end{tabular}

ambCO ambient carbon monoxide, exhCO exhaled carbon monoxide

${ }^{a}$ crude values

badjusted values

morning hours. This high baseline exhCO compared to the cut-off value used in evaluating the success of smoking cessation, and the pre-post work shift difference supports the clinical relevance of air pollution exposure for commercial motorcycle riders and other groups who work on and/or live near roads with heavy traffic.

This study also showed that measurement of exhaled $\mathrm{CO}$ is feasible in a limited resource setting. The level of carboxyhemoglobin can be calculated from the CoburnForster-Kane Equation. We were able to measure the baseline exhaled $\mathrm{CO}$ and the exhaled $\mathrm{CO}$ after $8 \mathrm{~h}$ in individuals exposed to OAP. Indeed, study participants were asked to come into our local laboratory in Benin for the measurement. This can be done routinely in a health care center with a relatively inexpensive device and low-cost disposable mouthpieces. In a patient for whom the healthcare provider suspected that exposure to OAP is a risk factor, exhCO measurement can be done to confirm exposure or for assessing intervention effectiveness. A cost-effectiveness analysis is needed to confirm whether this simple and noninvasive biomarker of OAP exposure is indeed useful in patient care.

We assumed that all the exposures happened outdoors based on the participant's declaration and the hours of measurements although we did not use a device like a GPS tracker to confirm it.

\section{Conclusion}

In non-smoking and non-cooking men exposed to OAP, exhCO can be used as a biomarker of short-term exposure to ambCO. Therefore, exhCO can be used to assess exposure to air pollution in less wealthy countries where this test is already routinely used in evaluating smoking cessation programs.

\section{Additional file}

Additional file 1: Questionnaire. (DOCX $11 \mathrm{~kb})$

\section{Abbreviations}

AmbCO: Ambient carbon monoxide; CO: Carbon monoxide; ExhCO: Exhaled carbon monoxide; OAP: Outdoor air pollution; ppm: Part per million;

SD: Standard deviation

\section{Acknowledgements}

The authors thank all the study participants.

\section{Funding}

This study was funded by the PATS MECOR small grant 2013, http:// www.breatheafrica.org/pats-mecor-2/.

\section{Availability of data and material}

The datasets used and/or analyzed during the current study are available from the corresponding author on reasonable request.

\section{Authors' contributions}

All the authors ( $L H, A F L, H V, W J, U K N, G S B, F B, B J R, H P, A E$, and SA) have contributed to the conception of the protocol and the writing of this article. The equipments were made available with GSB and BJR support. LH and AFL have collected the data. AE, HP performed the statistical analysis. All the authors read and approved the final manuscript.

\section{Competing interests}

The authors declare that they have no competing interests.

\section{Consent for publication}

Not applicable

\section{Ethics approval and consent to participate}

We received the approval of the ethics and research committee of the "Institut des Sciences Biomédicales Appliquées" (№6) prior the study and all participants provided written informed consent.

\section{Publisher's Note}

Springer Nature remains neutral with regard to jurisdictional claims in published maps and institutional affiliations.

\section{Author details}

${ }^{1}$ Unit of Teaching and Research in Occupational and Environmental Health, Department of Public Health, Faculty of Health Sciences, University of Abomey-Calavi, Cotonou, Benin. ${ }^{2}$ Institut Regional de Santé Publique, University of Abomey Calavi, Cotonou, Benin. ${ }^{3}$ Laboratoire de Biochimie et de Biologie Moléculaire, FAST/UAC, Cotonou, Benin. ${ }^{4}$ Department of Internal Medicine, Egerton University, Njoro, Kenya. ${ }^{5}$ Department of Internal Medicine, Federal Teaching Hospital, Abakaliki, Ebonyi State, Nigeria. 'iverpool School of Tropical Medicine, Liverpool, UK. ${ }^{7}$ Division of Environmental Health Sciences, School of Public Health, University of California, Berkeley, USA. 
Received: 23 September 2016 Accepted: 6 April 2017

\section{Published online: 17 April 2017}

\section{References}

1. United Nations. 2014. [15 March 2016]. Available from: www.un.org/en/ development/desa/news/population/world-urbanization-prospects-2014 html.

2. WHO. 68th world health assembly. 2015.

3. Lawin H, Agodokpessi G, Ayelo P, Kagima J, Sonoukon R, Mbatchou Ngahane BH, et al. A cross-sectional study with an improved methodology to assess occupational air pollution exposure and respiratory health in motorcycle taxi driving. Sci Total Environ. 2016;550:1-5.

4. Leary PJ, Kaufman JD, Barr RG, Bluemke DA, Curl CL, Hough $C L$, et al. Traffic-related air pollution and the right ventricle. The multi-ethnic study of atherosclerosis. Am J Respir Crit Care Med. 2014:189(9): 1093-100.

5. Agodokpessi G, Adjobimey M, Hinson V, Fayomi B, Gninafon M. Air pollution and respiratory disease in a tropical urban setting in Cotonou, Benin. Med Trop (Mars). 2011;71(1):41-4.

6. Loomis D, Grosse Y, Lauby-Secretan B, Ghissassi FE, Bouvard V, BenbrahimTallaa $L$, et al. The carcinogenicity of outdoor air pollution. Lancet Oncol. 2013:14(13):1262-3.

7. IARC. IARC Scientific Publication No. 161 Air Pollution and Cancer. 2013.

8. Scarpa MC, Kulkarni N, Maestrelli P. The role of non-invasive biomarkers in detecting acute respiratory effects of traffic-related air pollution. Clin Exp Allergy. 2014:44(9):1100-18.

9. Chen CC, Chang CH, Tsai YC, Tseng CW, Tu ML, Wang CC, et al. Utilizing exhaled carbon monoxide measurement with self-declared smoking cessation: enhancing abstinence effectiveness in Taiwanese outpatients. Clin Respir J. 2015;9(1):7-13.

10. Ripoll J, Girauta H, Ramos M, Medina-Bombardo D, Pastor A, Alvarez-Ossorio C, et al. Clinical trial on the efficacy of exhaled carbon monoxide measurement in smoking cessation in primary health care. BMC Public Health. 2012;12:322.

11. Bauer I, Pannen BH. Bench-to-bedside review: carbon monoxide-from mitochondrial poisoning to therapeutic use. Crit Care (London, England). 2009;13(4):220.

12. Clayton CE, Carraway MS, Suliman HB, Thalmann ED, Thalmann KN, Schmechel $\mathrm{DE}$, et al. Inhaled carbon monoxide and hyperoxic lung injury in rats. Am J Physiol Lung Cell Mol Physiol. 2001;281(4):L949-57.

13. Lawther PJ. Carbon monoxide. Br Med Bull. 1975;31(3):256-60.

14. Underner M, Peiffer $\mathrm{G}$. Interpretation of exhaled $\mathrm{CO}$ levels in studies on smoking. Rev Mal Respir. 2010;27(4):293-300.

15. Lee A, Sanchez TR, Shahriar MH, Eunus M, Perzanowski M, Graziano J. A cross-sectional study of exhaled carbon monoxide as a biomarker of recent household air pollution exposure. Environ Res. 2015;143(Pt A):107-11.

16. Zhang Q, Li L, Smith M, Guo Y, Whitlock G, Bian Z, et al. Exhaled carbon monoxide and its associations with smoking, indoor household air pollution and chronic respiratory diseases among 512,000 Chinese adults. Int J Epidemiol. 2013;42(5):1464-75.

17. Fourn L, Fayomi EB. Air pollution in urban area in Cotonou and Lokossa, Benin. Bull Soc Pathol Exot. 2006;99(4):264-8.

18. Ayi Fanou L, Mobio TA, Creppy EE, Fayomi B, Fustoni S, Møller P, et al. Survey of air pollution in Cotonou, Benin-air monitoring and biomarkers. Sci Total Environ. 2006;358(1-3):85-96.

19. Miller MR, Hankinson J, Brusasco V, Burgos F, Casaburi R, Coates A, et al. Standardisation of spirometry. Eur Respir J. 2005;26(2):319-38.

20. Deveci SE, Deveci F, Acik Y, Ozan AT. The measurement of exhaled carbon monoxide in healthy smokers and non-smokers. Respir Med. 2004;98(6):551-6.

\section{Submit your next manuscript to BioMed Central and we will help you at every step:}

- We accept pre-submission inquiries

- Our selector tool helps you to find the most relevant journal

- We provide round the clock customer support

- Convenient online submission

- Thorough peer review

- Inclusion in PubMed and all major indexing services

- Maximum visibility for your research

Submit your manuscript at www.biomedcentral.com/submit 